\title{
Body image dissatisfaction and depression in postbariatric patients is associated with less weight loss and a desire for body contouring surgery
}

Citation for published version (APA):

Monpellier, V. M., Antoniou, E. E., Mulkens, S., Janssen, I. M. C., van der Molen, A. B. M., \& Jansen, A. T. M. (2018). Body image dissatisfaction and depression in postbariatric patients is associated with less weight loss and a desire for body contouring surgery. Surgery for Obesity and Related Diseases, 14(10), 1507-1515. https://doi.org/10.1016/j.soard.2018.04.016

Document status and date:

Published: 01/10/2018

DOI:

10.1016/j.soard.2018.04.016

Document Version:

Publisher's PDF, also known as Version of record

Document license:

Taverne

Please check the document version of this publication:

- A submitted manuscript is the version of the article upon submission and before peer-review. There can be important differences between the submitted version and the official published version of record.

People interested in the research are advised to contact the author for the final version of the publication, or visit the DOI to the publisher's website.

- The final author version and the galley proof are versions of the publication after peer review.

- The final published version features the final layout of the paper including the volume, issue and page numbers.

Link to publication

\footnotetext{
General rights rights.

- You may freely distribute the URL identifying the publication in the public portal. please follow below link for the End User Agreement:

www.umlib.nl/taverne-license

Take down policy

If you believe that this document breaches copyright please contact us at:

repository@maastrichtuniversity.nl

providing details and we will investigate your claim.
}

Copyright and moral rights for the publications made accessible in the public portal are retained by the authors and/or other copyright owners and it is a condition of accessing publications that users recognise and abide by the legal requirements associated with these

- Users may download and print one copy of any publication from the public portal for the purpose of private study or research.

- You may not further distribute the material or use it for any profit-making activity or commercial gain

If the publication is distributed under the terms of Article $25 \mathrm{fa}$ of the Dutch Copyright Act, indicated by the "Taverne" license above, 
Original article

\title{
Body image dissatisfaction and depression in postbariatric patients is associated with less weight loss and a desire for body contouring surgery
}

\author{
Valerie M. Monpellier, M.D. ${ }^{\mathrm{a}, \mathrm{b}, *}$, Evangelia E. Antoniou, M.Sc., Ph.D. ${ }^{\mathrm{c}, \mathrm{d}}$, \\ Sandra Mulkens, M.Sc., Ph.D. ${ }^{b}$, Ignace M.C. Janssen, M.D ${ }^{\mathrm{a}, \mathrm{e}}$, Aebele B. Mink van der \\ Molen, M.D., Ph.D. ${ }^{\mathrm{f}, \mathrm{g}}$, Anita T.M. Jansen, M.Sc., Ph.D. ${ }^{\mathrm{b}}$ \\ ${ }^{a}$ Nederlandse Obesitas Kliniek, Huis ter Heide, Utrecht, the Netherlands \\ ${ }^{b}$ Faculty of Psychology and Neuroscience, Maastricht University, Maastricht, the Netherlands \\ ${ }^{c}$ Department of Epidemiology, Care and Public Health Research Institute (CAPHRI), Maastricht University, Maastricht, the Netherlands \\ ${ }^{d}$ Julius Center for Health Sciences and Primary Care, University Medical Center, Utrecht, the Netherlands \\ ${ }^{e}$ Department of Surgery, Nederlandse Obesitas Kliniek West, The Hague, The Netherlands \\ ${ }^{f}$ Department of Plastic, Reconstructive Surgery and Hand surgery, University Medical Center Utrecht, Utrecht, the Netherlands \\ ${ }^{g}$ Department of Plastic, Reconstructive Surgery and Hand surgery, Sint Antonius Hospital, Nieuwegein, the Netherlands \\ Received 1 December 2017; received in revised form 18 April 2018; accepted 20 April 2018
}

Abstract

Background: Overhanging skin in postbariatric patients leads to a negative body image. In patients with obesity, negative body image is related to more depressive symptoms and a higher weight. This relationship might also be important in postbariatric patients, because improvement of body image via body contouring surgery (BCS) could lead to better weight loss results.

Objectives: To evaluate the relationship between body image, depressive symptoms, and weight loss in a postbariatric population, focusing on desire for BCS.

Setting: Outpatient clinic.

Methods: One thousand twenty-four primary bariatric surgery patients were contacted, and 590 patients agreed to participate and filled in online questionnaires regarding body image (Body Shape Questionnaire and Multidimensional Body-Self Relations Questionnaire-Appearance Scales) and depression (Beck Depression Inventory-II). Differences between patients who had BCS, patients who desired BCS, and patients who did not desire BCS were studied. The mediating role of body image in the association between percentage total weight loss and depressive symptoms was assessed via a 2-mediator model.

Results: There was a desire for BCS in 368 patients $(62.4 \%)$; these patients had significantly lower scores on appearance evaluation and body image satisfaction scales and showed more depressive symptoms. Patients without a desire $(n=157,26.6 \%)$ had lowest rates of depressive symptoms and a more positive body image. Sixty-five patients $(11.0 \%)$ had undergone BCS. In the patients who desired BCS, percentage total weight loss was negatively affected by depressive symptoms via appearance evaluation and body-area satisfaction.

\footnotetext{
${ }^{*}$ Correspondence: Valerie Maureen Monpellier, Nederlandse Obesitas Kliniek, postbus 601, 3700 AP Zeist, the Netherlands.

E-mail address: vmonpellier@obesitaskliniek.nl (V.M. Monpellier).
} 
Conclusions: There are striking differences regarding body image satisfaction and depressive symptoms when comparing postbariatric patients and without desire for BCS. Body image satisfaction is associated with less depressive symptoms in all postbariatric patients. In patients who desired BCS, body image is one of the mediators of the relationship between percentage total weight loss and depressive symptoms. Therefore, body image should be taken seriously and be part of outcome assessment in postbariatric patients. (Surg Obes Relat Dis 2018;14:1507-1515.) (C) 2018 American Society for Bariatric Surgery. Published by Elsevier Inc. All rights reserved.

The positive effects of bariatric surgery, including significant weight loss and resolution of co-morbidities, have been well established $[1,2]$. However, the massive weight loss can lead to excess skin, which may negatively affect patients' well-being by causing medical, functional, and psychological problems [3-6]. Body contouring surgery (BCS) is the only treatment for restoration of the contour of the body and is desired by a large part of the postbariatric population [6-14]. Yet, only a small portion $(18 \%-33 \%)$ of postbariatric patients actually undergoes $\mathrm{BCS}$; the high costs of these procedures are considered a major reason for this reluctance $[6,8,12,15]$.

After BCS, patients show improved functional status, better body image, and higher quality of life, both in the short and long term [12,16-26]. More importantly, BCS patients have better weight loss maintenance than patients who do not undergo BCS after bariatric surgery [14,21,27]. Why BCS results in better weight loss maintenance has never been studied.

Weight and depression are strongly correlated in patients with obesity (higher weight indicating more depressive symptoms), and several studies found that this relationship is at least partly mediated by body image [28-33]. In obese patients, there are more depressive symptoms when body image satisfaction is low. Depressive symptoms, in turn, are known to negatively affect weight $[14,21,28-31,34]$.

In postbariatric patients extensive overhanging skin leads to a negative body image and could thereby lead to (more) depressive symptoms. However, research regarding the relationship between body image and depressive symptoms in postbariatric patients is sparse. One study assessed body image in postbariatric patients with complaints of excess skin, and it was found that a negative body image was related to more depressive symptoms and secondarily to weight regain [34]. Although this study was carried out in a relatively small sample, it does show that body image might play an important role in the well-being of postbariatric patients. It is unknown, though, whether this is true for all postbariatric patients. Do patients who desire BCS differ from patients who have no desire for BCS with regard to body image? In addition, to the best of our knowledge, no studies have been conducted assessing the role of body image in the relationship between weight loss and depressive symptoms in a postbariatric population.
Therefore, the goal of this study was to evaluate body image, depressive symptoms, and weight loss in a postbariatric population, and to compare patients who had BCS with patients who desire BCS and patients who do not desire BCS on these variables. Second, we assessed the mediating role of body image in the relationship between weight loss and depressive symptoms for these groups.

We hypothesized that the relationship between weight loss and depressive symptoms would be partly mediated by body image in the population who has not undergone BCS. This hypothesis was based on previous research in patients with obesity, in which the relationship between weight and depression was partially mediated by body image [28-33]. In the population who already had BCS, we expected a better body image and no relationship between weight and depressive symptoms.

\section{Methods}

\section{Standard treatment}

Patients were all treated at the Nederlandse Obesitas Kliniek (Dutch Obesity Clinic). The Nederlandse Obesitas Kliniek is the largest outpatient clinic for treatment of bariatric patients in the Netherlands. All patients follow pre- and postoperative group counseling by a specialized multidisciplinary team consisting of a dietician, a psychologist, a physical therapist, and a medical doctor. The data used for this study were part of a large cross-sectional study. The Psychology Ethics Committee of Maastricht University approved the study (ECP 06_11_2014).

\section{Patient selection}

Patients were selected from a prospective database. Because BCS is usually performed 12 months after stabilization of the bodyweight, patients who had a primary bariatric procedure 2 to 3 years before the start of the study were selected for participation. The study began on January 2, 2015, to ensure follow-up was at least 2 years; patients who had undergone a bariatric procedure between October 2011 and November 2012 were selected.

Patients were excluded if weight measures before and/or 1 year after bariatric surgery were not available. 
Table 1

Overview of questionnaires used with score range and explanation of scoring.

\begin{tabular}{lcc}
\hline Body Shape Questionnaire & & \\
Total score & $16-96$ & Higher score means more concerns about shape \\
Multidimensional Body-Self Relations Questionnaire-Appearance Scales \\
Appearance evaluation & $1-5$ & Higher score indicates more positive evaluation \\
Appearance orientation & $1-5$ & Higher score indicates more investment \\
Body-area satisfaction scale & $1-5$ & Higher score indicates more satisfaction \\
Overweight preoccupation & $1-5$ & Higher score indicates more preoccupation \\
Self-classified weight & $1-5$ & Higher score indicates higher weight \\
Beck Depression Inventory II & & \\
Total score & $0-63$ & Higher score means more depressive symptoms \\
\hline
\end{tabular}

There were 1334 patients eligible for inclusion in the study; 1024 patients were successfully contacted by electronic invitations. A total of 689 patients responded and $590 / 1024$ patients $(58 \%)$ agreed to participate, signed informed consent, and were included in the study.

\section{Data collection}

Demographic characteristics and weight measurements before and at 12 and 24 months after bariatric surgery were collected from the prospective database. Body mass index (BMI), change in BMI, percentage total weight loss (\%TWL), and percentage excess weight loss were calculated according to current guidelines [35].

Results for the questionnaires were electronically collected after patients agreed to participation.

\section{Questionnaires}

\section{Body contouring surgery}

To assess desire for BCS, patients were asked whether they wanted to undergo plastic surgery because of overhanging skin. It was also assessed if they had already undergone plastic surgery for overhanging skin. Current weight was also assessed here.

\section{Body image}

\section{Body Shape Questionnaire}

The Body Shape Questionnaire was used to evaluate concerns about body shape [36]. This questionnaire consists of 16 questions, to be answered on a 6-point Likert scale, resulting in a total score ranging from 16 to 96 points. A higher score means more concerns about body shape (Table 1). The Body Shape Questionnaire has been used for both obese and postbariatric population and has shown good validity and reliability [36-38].

\section{Multidimensional Body-Self Relations}

Questionnaire-Appearance Scales

The Multidimensional Body-Self Relations Questionnaire-Appearance Scales gives insight into body image concerns and has good validity and reliability $[39,40]$. The Multidimensional Body-Self Relations Questionnaire-Appearance Scales have been used in both bariatric and body contouring populations [23,32,41]. This questionnaire consists of 34 items, which are scored on a 5-point Likert scale, and scores for each subscale range from 1 to 5 points (Table 1). The 5 subscales are as follows: (1) appearance evaluation: assesses feelings of physical attractiveness (higher score indicates more positive feelings of attractiveness); (2) appearance orientation: assesses extend of investment in appearance (higher score indicates more investment); (3) overweight preoccupation: reflects the preoccupation with overweight cognitions (higher score indicates more preoccupation); (4) self-classified weight: reflects how the patient perceives and labels weight (higher score indicates higher weight); and (5) body-area satisfaction scale: satisfaction with several aspects of appearance (higher score indicates more satisfaction).

\section{Depressive symptoms}

The Beck Depression Inventory-II was used to evaluate depressive symptoms $[42,43]$. The questionnaire consists of 21 items, and each item can be scored from 0 to 3 points (Table 1). A score $<13$ indicates no or minimal depressive symptoms, a score between 14 and 19 indicates light symptoms, a score between 20 and 28 indicates moderate symptoms, and a score $>29$ indicates severe depressive symptoms [42].

\section{Statistical analyses}

Descriptive statistics were calculated to summarize baseline characteristics. Independent samples $t$ tests and $\chi^{2}$ tests were used to compare the characteristics of the patients who were included and the patients who were excluded to ensure this did not influence the results.

Subsequently, the included population was divided into the following 3 groups: (1) patients who already underwent BCS (BCS group), (2) patients who desired BCS (D 


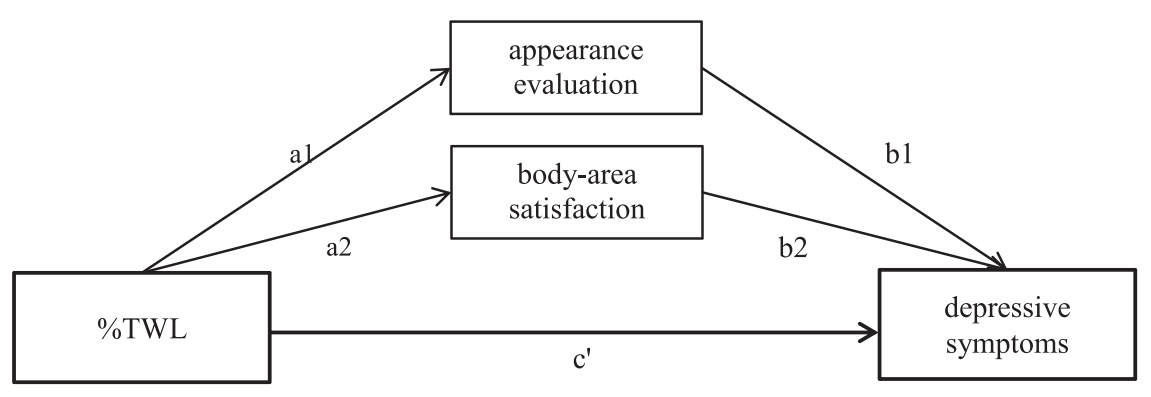

Fig. 1. Two-mediator model of the relationship between percentage of total weight loss (\%TWL) and depressive symptoms.

group), and (3) patients without a desire for BCS (ND group).

Differences in age, weight change before and after bariatric surgery, body image, and depressive symptoms between the 3 groups were calculated using one-way analysis of the variance. Sex and type of bariatric surgery were compared using a $\chi^{2}$ analysis.

Subsequently, the relationship between depressive symptoms and \%TWL was assessed with a mediation analysis. A mediation analysis assesses how an independent variable affects a dependent variable, through intervening variables (the mediators) [44]. In this study, the mediating role of body image on the relationship between \%TWL and depressive symptoms was assessed via a 2-mediator model (see Fig. 1).

The appearance evaluation scale and body-area satisfaction scale were chosen as mediators for 2 reasons: first, because these scales reflect how patients feel about their bodies, lower scores reflect a more negative body image [39]; second, because these variables are known to change after bariatric surgery and BCS $[20,23,32,45]$.

Pearson's correlations between \%TWL, depressive symptoms, and body image (appearance evaluation and body-area satisfaction scale) were calculated for each of the groups. In case of significant correlations, a mediation analysis was conducted for that specific group. Baseline BMI and sex were included as covariates in this analysis. Bootstrapping was used to obtain confidence intervals [44]. Mediation was considered to have occurred if the $95 \%$ bias corrected confidence intervals for the effects generated did not contain zero. Findings of other analysis were considered statistically significant if $P<.05$. All analyses were performed using SPSS, version 23 (IBM Corp., Armonk, NY, USA)

\section{Results}

\section{Study population}

There were no significant differences between the included $(n=590)$ and excluded $(n=744)$ patients with regard to age, follow-up time since bariatric surgery, baseline $\mathrm{BMI}$, and BMI at 12 and 24 months after bariatric surgery.
There were significantly more females in the included population (81.2\% compared with $75.3 \% ; P=.01$ ).

Mean age of the included patients was 47.7 years. Before bariatric surgery, the mean BMI was $45.4 \mathrm{~kg} / \mathrm{m}^{2}$. Most patients had undergone a RYGB $(\mathrm{n}=511,86.9 \%), 66$ patients $(11.2 \%)$ had undergone a gastric sleeve, and 11 patients $(1.9 \%)$ had undergone laparoscopic adjustable banding. Mean BMI was $31.8 \mathrm{~kg} / \mathrm{m}^{2}$ at 12 -month follow-up and $31.1 \mathrm{~kg} / \mathrm{m}^{2}$ at 24-month follow-up. At the time of the current survey the mean follow-up was 32 months, BMI was $30.7 \mathrm{~kg} / \mathrm{m}^{2}$, and TWL was $32.1 \%$.

\section{Patient characteristics}

A total of 65 patients (11.0\%) had undergone BCS (BCS group). There was a desire for BCS in 368 patients $(62.4 \%$, D group), and no desire for BCS in $26.6 \%$ of the patients ( $\mathrm{n}=157$, ND group).

The ND group contained the lowest rate of females (68.2\%, $P<.001)$, compared with the D group (84.5\%) and the BCS group (93.8\%; Table 2). Age, follow-up time, and type of bariatric procedure were not significantly different between the 3 groups. BMI before bariatric surgery was $46.2 \mathrm{~kg} / \mathrm{m}^{2}$ in the D group, which was significantly higher compared with the ND group (mean: $44.1 \mathrm{~kg} / \mathrm{m}^{2}$, $P=.001$ ) and the BCS group (mean: $43.9 \mathrm{~kg} / \mathrm{m}^{2}, P=.011$ ). Patients who underwent BCS had the lowest BMI at all follow-up moments. Weight loss was higher in the D group compared with the ND group: change in BMI $15.1 \mathrm{~kg} / \mathrm{m}^{2}$ versus $12.8 \mathrm{~kg} / \mathrm{m}^{2}(P<.001)$ and TWL $32.6 \%$ versus $28.9 \%(P<.001)$. In the BCS group, weight loss was highest (TWL 36.8\%).

\section{Body image}

The mean Body Shape Questionnaire score was 49.5 in the D group, which was significantly higher compared with the BCS group $(40.2 ; P<.001)$ and the ND group (30.1; $P<.001$; Table 3). The difference between the BCS group and the ND group was also significant $(P<$ $.001)$. There was a marked concern about shape (score $>66$ ) in $15.7 \%$ of the D group. In the ND group $1.4 \%$ had a 
Table 2

Demographic characteristics of the total population and of the 3 groups, presented in mean \pm standard deviation or percentage $(\mathrm{n})$.

\begin{tabular}{llll}
\hline & BCS group $(\mathrm{n}=65)$ & D group $(\mathrm{n}=368)$ & ND group $(\mathrm{n}=157)$ \\
\hline Females, \% (n) & $93.8(61)^{*}$ & $84.5(311)^{\dagger}$ & $68.2(107)^{\ddagger}$ \\
Age, yr & $45.0 \pm 11.4$ & $47.1 \pm 10.6^{\dagger}$ & $49.8 \pm 10.5^{\ddagger}$ \\
RYGB, \% (n) & $85.9(55)$ & $87.8(323)$ & $84.7(133)$ \\
FU, mo & $32.6 \pm 3.7$ & $32.3 \pm 3.9$ & $32.4 \pm 3.7$ \\
BMI before BS, kg/m ${ }^{2}$ & $43.9 \pm 6.1^{*}$ & $46.2 \pm 5.8^{\dagger}$ & $44.1 \pm 6.3$ \\
BMI 12-mo FU, kg/m & $29.8 \pm 5.3^{*}$ & $32.2 \pm 5.2$ & $31.6 \pm 5.7$ \\
BMI 24-mo FU, kg/m ${ }^{2}$ & $28.5 \pm 4.6^{*}$ & $31.2 \pm 5.4$ & $31.9 \pm 6.0^{\dagger}$ \\
Current BMI, kg/m ${ }^{\dagger}$ & $27.6 \pm 4.5^{*}$ & $31.1 \pm 5.6$ & $31.3 \pm 5.6^{\dagger}$ \\
$\Delta$ BMI, kg/m 2 & $16.3 \pm 5.1$ & $15.1 \pm 4.9^{\dagger}$ & $12.8 \pm 4.6^{\dagger}$ \\
Current EWL, \% & $89.1 \pm 20.1^{*}$ & $73.9 \pm 22.6$ & $69.9 \pm 2.7^{\dagger}$ \\
Current TWL, \% & $36.8 \pm 8.0^{*}$ & $32.6 \pm 9.1^{\dagger}$ & $28.9 \pm 9.3^{\dagger}$ \\
\hline
\end{tabular}

$\mathrm{BCS}=$ body contouring surgery; $\mathrm{BCS}$ group = patients who already underwent $\mathrm{BCS}$; $\mathrm{D}$ group = patients who desired BCS; ND group= patients without a desire for $B C S$; RYGB = Roux-en-Y gastric bypass; $\mathrm{FU}=$ follow-up; $\mathrm{BMI}=$ body mass index; $\mathrm{BS}=$ bariatric surgery; $\triangle \mathrm{BMI}=$ difference between current $\mathrm{BMI}$ and $\mathrm{BMI}$ before bariatric surgery; $\mathrm{EWL}=$ excess weight loss; $\mathrm{TWL}=$ total weight loss.

* Significant difference compared with $\mathrm{D}$ group, $P<.05$.

†ignificant difference compared with ND group, $P<.05$.

${ }^{\ddagger}$ Significant difference compared with BCS-group, $P<.05$.

Table 3

Body image and depressive symptoms of the 3 groups, presented as mean scores \pm standard deviation.

\begin{tabular}{llll}
\hline & BCS group $(\mathrm{n}=65)$ & D group $(\mathrm{n}=368)$ & ND group $(\mathrm{n}=157)$ \\
\hline $\begin{array}{l}\text { Body Shape Questionnaire* } \\
\text { MBSRQ-AS }\end{array}$ & $40.2 \pm 18.4^{\dagger}$ & $49.5 \pm 16.9^{\ddagger}$ & $30.1 \pm 12.8^{\S}$ \\
$\quad$ & & \\
Appearance evaluation & & $2.58 \pm .72^{\ddagger}$ & $3.26 \pm .58$ \\
Appearance orientation $^{* *}$ & $3.23 \pm .67^{\dagger}$ & $3.74 \pm .56^{\ddagger}$ & $3.27 \pm .61^{\S}$ \\
Body-area satisfaction scale $^{\natural}$ & $3.14 \pm .68^{\dagger}$ & $2.68 \pm .56^{\ddagger}$ & $3.22 \pm .57$ \\
Overweight preoccupation* $^{\dagger}$ & $2.89 \pm .76$ & $2.98 \pm .83^{\ddagger}$ & $2.41 \pm .79^{\S}$ \\
$\quad$ Self-classified weight* & $3.24 \pm .64^{\dagger}$ & $3.86 \pm .74$ & $3.76 \pm .73^{\S}$ \\
Beck Depression Inventory II* & $12.1 \pm 11.0$ & $14.6 \pm 11.8^{\ddagger}$ & $9.1 \pm 11.0$ \\
\hline
\end{tabular}

$\mathrm{BCS}=$ body contouring surgery; $\mathrm{BCS}$ group $=$ patients who already underwent $\mathrm{BCS}$; $\mathrm{D}$ group $=$ patients who desired BCS; ND group= patients without a desire for BCS; MBSRQ-AS: Multidimensional BodySelf Relations Questionnaire-Appearance Scales.

† Significant difference compared with D-group, $P \leq .005$.

${ }^{\ddagger}$ Significant difference compared with ND group, $P \leq .001$.

$\S$ Significant difference compared with BCS group, $P \leq .001$.

${ }^{\mathbb{I}}$ Higher score is positive (positive body image, more focus on appearance and better satisfaction with body).

* Higher score is negative (more concerns about shape, more depressive symptoms, more preoccupation, and higher weight).

marked concern, and in BCS group this was $10.0 \%$ of the population $(P<.001)$.

For the Multidimensional Body-Self Relations Questionnaire, patients in the $\mathrm{D}$ group had a mean score of 2.58 on appearance evaluation, which was significantly lower than the ND group (mean 3.26, $P<.001$ ) and the BCS group (mean 3.23, $P<.001$; Table 3). They also had a significantly lower average score on the body area satisfaction scale at 2.68 versus 3.22 in the ND group and 3.14 in BCS group $(P<.001$ in all). Patients with no desire for BCS scored lowest on the appearance orientation (mean score 3.27) and overweight preoccupation (mean score 2.41). Patients in the D group had the highest score (mean 3.86) on the weight classification; the BCS group scored significantly lower with a mean score of $3.24(P<.001)$.

\section{Depressive symptoms}

The Beck Depression Inventory-II (BDI) score was higher in the D group (14.6), compared with the ND group (9.1, $P<.001$; Table 3 ). The BCS group had a mean score of 12.1 ; this was not significantly different from either of the other groups. Subsequently, 
Table 4

Mediation effect of appearance evaluation and body-area satisfaction on the association between depression and percentage total weight loss in the desire group.

\begin{tabular}{|c|c|c|c|c|}
\hline & \multirow[b]{2}{*}{ Coefficient } & \multirow{2}{*}{$\begin{array}{l}\text { Product of coefficients } \\
\text { Standard error }\end{array}$} & \multicolumn{2}{|c|}{$\begin{array}{l}\text { Bootstrapping } \\
\text { Bias corrected } 95 \% \text { confidence } \\
\text { interval }\end{array}$} \\
\hline & & & Lower & Upper \\
\hline \multicolumn{5}{|l|}{ Indirect effects } \\
\hline Appearance evaluation & $-.04^{*}$ & .02 & -.10 & -.01 \\
\hline Body-area satisfaction & $-.11^{\dagger}$ & .04 & -.20 & -.04 \\
\hline Total & $-.15^{\dagger}$ & .04 & -.23 & -.07 \\
\hline \multicolumn{5}{|l|}{ Contrast } \\
\hline $\begin{array}{l}\text { Appearance evaluation versus } \\
\text { Body-area satisfaction }\end{array}$ & .07 & .05 & -.02 & .18 \\
\hline
\end{tabular}

1000 bootstrap samples; analysis adjusted for body mass index before bariatric surgery and sex.

$* P<.01$

${ }^{\dagger} P<.001$.

BDI scores were divided into 4 categories, ranging from mild to severe depressive symptoms. In the D group 26.9\% had moderate to severe depressive symptoms compared with only $10.4 \%$ in the ND group and $28.3 \%$ in the BCS group $(P<.001)$.

\section{Correlations}

In the patients with a desire for BCS, \% TWL correlated negatively with depressive symptoms $(\mathrm{r}=-.196, P<$ $.001)$ and positively with appearance evaluation $(\mathrm{r}=.159$, $P=.003)$ and body area satisfaction $(\mathrm{r}=.223, P<.001)$. This means that more weight loss is associated with less depression and a more positive body image. Appearance evaluation and body area satisfaction both correlated negatively with BDI $(\mathrm{r}=-.361, P<.001$ and $\mathrm{r}=-.439$, $P<.001$, respectively), meaning that a more negative body evaluation is associated with more depressed symptoms.

In the ND group, \% TWL was significantly (positively) related to appearance evaluation $(\mathrm{r}=.227, P=.006)$, meaning that more weight loss was significantly associated with a more positive appearance evaluation. There were no significant correlations of \% TWL with BDI and body area satisfaction, meaning that weight loss was not associated with depressive symptoms and body area satisfaction. There was a negative correlation between appearance evaluation and BDI $(\mathrm{r}=-.398, P<.001)$ and body area satisfaction and BDI $(\mathrm{r}=-.432, P<.001)$; lower appearance evaluation and lower body area satisfaction were related to more depressive symptoms.

In the BCS group, there was a significant correlation of \%TWL with body area satisfaction $(\mathrm{r}=.302, P=.019)$, meaning that more weight loss is associated with higher body area satisfaction. No significant correlation of \%TWL with appearance evaluation or BDI was found, so the weight loss was not related to appearance evaluation or depression in this group. Again, there was a significant, negative correlation between the appearance evaluation and BDI $(\mathrm{r}=-.519, P<.001)$ and body area satisfaction and BDI $(\mathrm{r}=-.557, P<.001)$.

\section{Mediation effect of body image}

Because in the D group all variables (\% TWL, depressive symptoms, appearance evaluation, and body area satisfaction) were significantly correlated, a mediation analysis was conducted for this group. The total indirect effect of \%TWL on depressive symptoms was -.15 , which leads to the rejection of the null hypothesis that the total indirect effect is $0(P=.003)$. Therefore, depressive symptoms are partly, via the mediators of appearance evaluation and body-area satisfaction, influenced by \%TWL. This means that a higher \%TWL results in less depressive symptoms, via more positive feelings of attractiveness and higher body-area satisfaction. The specific indirect effect is -.04 through appearance evaluation and -.11 through body-area satisfaction (Table 4). Of the mediators examined, both appearance evaluation $(P=.003)$ and body-area satisfaction $(P<.001)$ were important mediators. This relationship was not influenced by baseline BMI $(P=.267)$ or sex $(P=.996)$.

\section{Discussion}

The present study assessed body image, depressive symptoms, weight loss, and the relationship between these factors in a large postbariatric population, focusing on the desire for BCS. Our results show striking differences among patients who had BCS, patients who desired BCS, and patients who did not desire BCS. Patients with a desire for BCS had a more negative body image than patients who already had BCS and patients without a desire for BCS. The patients with a desire also showed more depressive symptoms than patients without a desire. Moreover, 
in the population with a desire for BCS, a higher \% TWL was related in less depressive symptoms via more positive feelings of attractiveness and higher body-area satisfaction. Thus, the relationship between weight loss and depressive symptoms was partly explained by body image. In all patients, a better body image was related to less depressive symptoms.

There was a desire for BCS in $>60 \%$ of the study population, which is in concordance with previous research [3,6-9]. The patients who desire BCS showed a higher prevalence of depressive symptoms compared with patients who did not desire BCS. Several studies have shown higher appearance evaluation and body-area satisfaction after bariatric surgery and BCS $[20,23,32,45]$. Our "desire" population had more concerns about their body, felt less attractive, and were less satisfied with their appearance compared with patients who had no desire for BCS and patients who already had BCS. The characteristics of the D group (negative body image and more depressive symptoms) are known to negatively affect bodyweight in patients with obesity [28-33].

Surprisingly, the patients who had undergone BCS showed some similarities with the patients who desired BCS. They both show higher appearance concerns and were both more preoccupied with overweight stigmata. Research has shown that after bariatric surgery and body contouring, appearance evaluation and body area satisfaction improve, but the overweight preoccupation might remain $[20,23]$. Thus, it could well be that the patients who desire BCS and the patients who have had BCS are basically the same type of patients, but body image in the BCS group has improved partly as a consequence of the body contouring procedure(s). However, these data are correlational, and therefore causal conclusions cannot be drawn.

Interestingly, more than a quarter of the studied patients did not have a desire for BCS; this group differs considerably from patients who already had BCS and the patients with a desire for BCS. These patients are less focused on their appearance and less preoccupied by overweight cognitions, even though they had the lowest weight loss and highest current BMI. Patients with a desire for BCS were even more preoccupied although they lost more weight and had a comparable BMI.

In the group with a desire for BCS, \%TWL, depressive symptoms, appearance evaluation, and body area satisfaction were all significantly correlated. Higher weight loss was related to less depressive symptoms and a more positive body image. In all 3 groups, more positive feelings of physical attractiveness and higher satisfaction with the body were related to fewer depressive symptoms. Thus, even in the population without a desire for BCS, a more negative body image is related to negative effect, as in the obese (prebariatric) population [28,30].

Our hypothesis was that, like in patients with obesity, body image would partly mediate the relationship between weight loss and depressive symptoms in the postbariatric patients who had not undergone BCS $[30,31]$. Our results show that only in the patients who have a desire for BCS is the association between \%TWL and depressive symptoms indeed partially mediated by body image: a higher weight loss was related to less depressive symptoms via a more positive body image. This was independent of sex and BMI before bariatric surgery. These results show the close relationship among weight, negative affect, and body image. This is the first step into analyzing the pathways by which patients who undergo BCS might have better weight loss maintenance.

The 3 groups of patients had a similar follow-up time, and the number of patients who underwent RYGB was equal. However, BMI before bariatric surgery was significantly different among the groups. Although this might have influenced preoperative body image and depressive symptoms, we cannot be certain about this because preoperative data collection was not part of this study.

A weakness of the present study is its cross-sectional design, making it impossible to draw conclusions about the causal nature of the associations. As a consequence of the cross-sectional nature, we have no knowledge of the body image and depressive symptoms before bariatric surgery. In addition, it could be discussed that we did not assess the actual amount of overhanging skin. However, our goal was to show the differences in the psychological consequences of the experience of excess skin in the postbariatric population. Moreover, research has shown that estimating excess skin is very difficult and does not correlate with the perception of the patient [46].

A strength of this study was the large number of participants and the relatively high response rate of this nationwide postbariatric population, with almost no differences between the included and excluded population.

\section{Conclusions}

This study shows that postbariatric patients differ in general body satisfaction. It seems that some postbariatric patients are rather satisfied with their bodies without BCS, while another group is not happy and desires BCS. The study further shows that body image is an important indicator of a patient's wellbeing after bariatric surgery, independent of the desire for BCS. However, body image has not been a standard part of outcome analysis in this population, and until recently there was no specific questionnaire to assess body image in the (post)bariatric patient. It is therefore unknown whether patients with a preoperative negative body image are also the patients who desire BCS the most and who will also benefit the most from it.

Body image should be considered an outcome parameter in assessing health-related quality of life in postbariatric patients. Future research should focus on body image both before and after bariatric surgery and study the pathway by 
which BCS improves long-term weight loss maintenance. It might also be of interest to find out whether interventions that increase body satisfaction should be part of pre- and postoperative care in this group of patients.

\section{Disclosures}

\section{The authors have no commercial associations that might be a conflict of interest in relation to this article.}

\section{References}

[1] Colquitt JL, Pickett K, Loveman E, Frampton GK. Surgery for weight loss in adults. Cochrane Database Syst Rev 2014;8:CD003641.

[2] Sjostrom L. Review of the key results from the Swedish Obese Subjects (SOS) trial - a prospective controlled intervention study of bariatric surgery. J Intern Med 2013;273(3):219-34.

[3] Kitzinger HB, Abayev S, Pittermann A, et al. After massive weight loss: patients' expectations of body contouring surgery. Obes Surg 2012;22(4):544-8.

[4] Pecori L, Serra Cervetti GG, Marinari GM, Migliori F, Adami GF. Attitudes of morbidly obese patients to weight loss and body image following bariatric surgery and body contouring. Obes Surg 2007;17(1):68-73.

[5] Klopper EM, Kroese-Deutman HC, Berends FJ. Massive weight loss after bariatric surgery and the demand (desire) for body contouring surgery. Eur J Plast Surg 2014;37(2):103-8.

[6] Staalesen T, Fagevik Olsen M, Elander A. Experience of excess skin and desire for body contouring surgery in post-bariatric patients. Obes Surg 2013;23(10):1632-44.

[7] Aldaqal SM, Samargandi OA, El-Deek BS, Awan BA, Ashy AA, Kensarah AA. Prevalence and desire for body contouring surgery in postbariatric patients in Saudi Arabia. $N$ Am J Med Sci 2012;4(2):94-8.

[8] Gusenoff JA, Messing S, O'Malley W, Langstein HN. Temporal and demographic factors influencing the desire for plastic surgery after gastric bypass surgery. Plast Reconstr Surg 2008;121(6):2120-6.

[9] Giordano S, Victorzon M, Stormi T, Suominen E. Desire for body contouring surgery after bariatric surgery: do body mass index and weight loss matter? Aesthet Surg J 2014;34(1):96-105.

[10] Wagenblast AL, Laessoe L, Printzlau A. Self-reported problems and wishes for plastic surgery after bariatric surgery. J Plast Surg Hand Surg 2014;48(2):115-21.

[11] Abela C, Stevens T, Reddy M, Soldin M. A multidisciplinary approach to post-bariatric plastic surgery. Int J Surg 2011;9(1):29-35.

[12] Azin A, Zhou C, Jackson T, Cassin S, Sockalingam S, Hawa R. Body contouring surgery after bariatric surgery: a study of cost as a barrier and impact on psychological well-being. Plast Reconstr Surg 2014;133(6):776e-782e.

[13] Gilmartin J, Bath-Hextall F, Maclean J, Stanton W, Soldin M. Quality of life among adults following bariatric and body contouring surgery: a systematic review. JBI Database System Rev Implement Rep 2016;14(11):240-70.

[14] Wiser I, Avinoah E, Ziv O, et al. Body contouring surgery decreases long-term weight regain following laparoscopic adjustable gastric banding: a matched retrospective cohort study. J Plast Reconstr Aesthet Surg 2016;69(11):1490-6.

[15] Gusenoff JA, Messing S, O'Malley W, Langstein HN. Patterns of plastic surgical use after gastric bypass: who can afford it and who will return for more. Plast Reconstr Surg 2008;122(3):951-8.

[16] Singh D, Zahiri HR, Janes LE, et al. Mental and physical impact of body contouring procedures on post-bariatric surgery patients. Eplasty 2012;12:e47.
[17] Stuerz K, Piza H, Kinzl JF. The impact of abdominoplasty after massive weight loss: a qualitative study. Ann Plast Surg 2013;71(5):547-9.

[18] Koller M, Schubhart S, Hintringer T. Quality of life and body image after circumferential body lifting of the lower trunk: a prospective clinical trial. Obes Surg 2013;23(4):561-6.

[19] Coriddi MR, Koltz PF, Chen R, Gusenoff JA. Changes in quality of life and functional status following abdominal contouring in the massive weight loss population. Plast Reconstr Surg 2011;128(2):520-6.

[20] Song P, Patel NB, Gunther S, et al. Body image \& quality of life: changes with gastric bypass and body contouring. Ann Plast Surg 2016;76(Suppl 3):S216-21.

[21] Balague N, Combescure C, Huber O, Pittet-Cuenod B, Modarressi A. Plastic surgery improves long-term weight control after bariatric surgery. Plast Reconstr Surg 2013;132(4):826-33.

[22] Modarressi A, Balague N, Huber O, Chilcott M, Pittet-Cuenod B. Plastic surgery after gastric bypass improves long-term quality of life. Obes Surg 2013;23(1):24-30.

[23] de Zwaan M, Georgiadou E, Stroh CE, et al. Body image and quality of life in patients with and without body contouring surgery following bariatric surgery: a comparison of pre- and post-surgery groups. Front Psychol 2014;5:1310.

[24] van der Beek ES, Geenen R, de Heer FA, van der Molen AB, van Ramshorst B. Quality of life long-term after body contouring surgery following bariatric surgery: sustained improvement after 7 years. Plast Reconstr Surg 2012;130(5):1133-9.

[25] van der Beek ES, Te Riele W, Specken TF, Boerma D, van Ramshorst B. The impact of reconstructive procedures following bariatric surgery on patient well-being and quality of life. Obes Surg 2010;20(1):36-41.

[26] Vierhapper MF, Pittermann A, Hacker S, Kitzinger HB. Patient satisfaction, body image, and quality of life after lower body lift: a prospective pre- and postoperative long-term survey. Surg Obes Relat Dis 2017;13(5):882-7.

[27] Froylich D, Corcelles R, Daigle CR, et al. Weight loss is higher among patients who undergo body contouring procedures after bariatric surgery. Surg Obes Relat Dis 2016;12(9):1731-6.

[28] Stunkard AJ, Wadden TA. Psychological aspects of severe obesity. Am J Clin Nutr 1992;55(2 Suppl):524S-532S.

[29] Wardle J, Waller J, Rapoport L. Body dissatisfaction and binge eating in obese women: the role of restraint and depression. Obes Res 2001;9(12):778-87.

[30] Friedman KE, Reichmann SK, Costanzo PR, Musante GJ. Body image partially mediates the relationship between obesity and psychological distress. Obes Res 2002;10(1):33-41.

[31] Sarwer DB, Wadden TA, Foster GD. Assessment of body image dissatisfaction in obese women: specificity, severity, and clinical significance. J Consult Clin Psychol 1998;66(4):651-4.

[32] Dixon JB, Dixon ME, O'Brien PE. Body image: appearance orientation and evaluation in the severely obese. Changes with weight loss. Obes Surg 2002;12(1):65-71.

[33] Jansen A, Havermans R, Nederkoorn C, Roefs A. Jolly fat or sad fat? Subtyping non-eating disordered overweight and obesity along an affect dimension. Appetite 2008;51(3):635-40.

[34] Ramalho S, Bastos AP, Silva C, et al. Excessive skin and sexual function: relationship with psychological variables and weight regain in women after bariatric surgery. Obes Surg 2015;25(7):1149-54.

[35] Brethauer SA, Kim J, El Chaar M, et al. Standardized outcomes reporting in metabolic and bariatric surgery. Obes Surg 2015;25(4):587-606.

[36] Cooper PJ, Taylor MJ, Cooper Z, Fairburn CG. The development and validation of the body shape questionnaire. Int J Eat Disord 1987;6(4):485.

[37] White MA, Masheb RM, Rothschild BS, Burke-Martindale CH, Grilo CM. The prognostic significance of regular binge eating in 
extremely obese gastric bypass patients: 12-month postoperative outcomes. J Clin Psychiatry 2006;67(12):1928-35.

[38] Hrabosky JI, Masheb RM, White MA, Rothschild BS, Burke-Martindale $\mathrm{CH}$, Grilo $\mathrm{CM}$. A prospective study of body dissatisfaction and concerns in extremely obese gastric bypass patients: 6- and 12-month postoperative outcomes. Obes Surg 2006;16(12):1615-21.

[39] Cash TF, Wood KC, Phelps KD, Boyd K. New assessments of weight-related body image derived from extant instruments. Percept Mot Skills 1991;73(1):235-41.

[40] Brown TA, Cash TF, Mikulka PJ. Attitudinal body-image assessment: factor analysis of the body-self relations questionnaire. J Pers Assess 1990;55(1-2):135-44.

[41] Neven K, Dymek M, leGrange D, Maasdam H, Boogerd AC, Alverdy J. The effects of Roux-en-Y gastric bypass surgery on body image. Obes Surg 2002;12(2):265-9.

[42] Beck AT, Steer RA, Brown GK. Manual for the Beck Depression Inventory-II. San Antonio: Psychological Corporation; 1996.
[43] Beck AT, Steer RA, Ball R, Ranieri W. Comparison of Beck Depression Inventories -IA and -II in psychiatric outpatients. J Pers Assess 1996;67(3):588-97.

[44] Preacher KJ, Hayes AF. Asymptotic and resampling strategies for assessing and comparing indirect effects in multiple mediator models. Behav Res Methods 2008;40(3):879-91.

[45] Song AY, Rubin JP, Thomas V, Dudas JR, Marra KG, Fernstrom MH. Body image and quality of life in post massive weight loss body contouring patients. Obesity (Silver Spring) 2006;14(9):1626-36.

[46] Biorserud C, Olbers T, Staalesen T, Elander A, Olsen MF. Understanding excess skin in postbariatric patients: objective measurements and subjective experiences. Surg Obes Relat Dis 2016;12(7):1410-17. 